\title{
Knockdown of MicroRNA-1 in the Hippocampus Ameliorates Myocardial Infarction Induced Impairment of Long- Term Potentiation
}

\author{
Ji-Chao Ma ${ }^{a}$ Ming-Jing Duan ${ }^{a} \quad K e-X i n L^{a} \quad$ Das Biddyut $^{a} \quad$ Shuai Zhang ${ }^{a}$ \\ Mei-Ling Yana Lin Yang ${ }^{a}$ Zhuo Jin ${ }^{a}$ Hong-Mei Zhao ${ }^{a}$ Si-Yu Huanga \\ Qiang Sun ${ }^{a}$ Dan Su ${ }^{a}$ Yi Xu $^{a}$ Yong-Hui Pan ${ }^{b}$ Jing $\mathrm{Ai}^{\mathrm{a}}$ \\ aDepartment of Pharmacology, The State-Province Key Laboratories of Biomedicine-Pharmaceutics \\ of China, College of Pharmacy of Harbin Medical University, Harbin, ${ }^{b}$ Department of Neurology, First \\ Clinical Medical College of Harbin Medical University, Harbin, China
}

\section{Key Words}

Heart $\cdot$ Hippocampus $\cdot$ Cognitive impairment $\cdot$ MicroRNA-1 $\cdot$ BDNF $・$ long-term potentiation

\begin{abstract}
Backgrounds/Aims: It has been reported that myocardial infarction (MI) is a risk factor for vascular dementia. However, the molecular mechanism remains largely unknown. Methods: MI mice were generated by ligation of the left coronary artery (LCA) for 4 weeks. Passive and active avoidance tests were performed to evaluate the cognitive ability of MI mice. A theta-burst stimulation (TBS) protocol was applied to elicit long-term potentiation (LTP) of the perforant pathway-dentate gyrus synapse (PP-DG). Western blot analysis was employed to assess protein levels. Results: In this study, we demonstrated that after 4 weeks of $\mathrm{MI}$, C57BL/6 mice had significantly impaired memory. Compared with the sham group, in vivo physiological recording in the $\mathrm{Ml}$ group revealed significantly decreased amplitude of population spikes (PS) with no effect on the latency and duration of the stimulus-response curve. The amplitude of LTP was markedly decreased in the MI group compared with the sham group. Further examination showed that the expression of the TBS-LTP-related proteins BDNF, GluA1 and phosphorylated GluA1 were all decreased in the MI group compared with those in the sham group. Strikingly, all these changes were prevented by hippocampal stereotaxic injection of an anti-miR-1 oligonucleotide fragment carried by a lentivirus vector (lenti-preAMO-1). Conclusion: MI induced cognitive decline and TBS-LTP impairment, and decreased BDNF and GluA1 phosphorylation levels from overexpression of $m i R$ - 1 ated were involved in this process.

(C) 2018 The Author(s)

J.-C. Ma and M.-J. Duan contributed equally to this work.

\begin{tabular}{ll}
\hline Jing Ai & Department of Pharmacology, (The State-Province Key Laboratories of Biomedicine-Pharmaceutics of China) \\
and Yong-Hui Pan & College of Pharmacy of Harbin Medical University, Harbin, Heilongjiang Province, 150086 (China) \\
& Tel. +86 451 8666-1354, Fax +86 451 8667-1354, E-Mail azhrbmu@126.com; aigui1993@126.com
\end{tabular}
\end{abstract}




\section{Introduction}

Since the concept of "cardiogenic dementia" was proposed in the late 1970s [1], large cohort clinical trials have revealed that cardiovascular diseases and cognitive impairment were closely associated [2-7]. More importantly, it was found that greater application of cardiovascular system medications could lower the probability of a dementia diagnosis [8, 9]. However, the molecular basis of this correlation is still unclear.

Myocardial infarction (MI) is the most prevalent of the various cardiovascular diseases, and it has been reported to be a risk factor leading to vascular dementia [10-12]. A previous animal study reported that after 3 months of ligation of the left coronary artery (LCA), there was significant cognitive impairment accompanied by altered $\beta$-amyloid metabolism, apoptosis and inflammation in mice, indicating an increased potential of dementia following MI [13]. Notably, MI induced brain damage on the $15^{\text {th }}$ day, which occurred before the cognitive deficiency was apparent 3 months after LCA. Since the most common clinical outcomes of MI are arrhythmia and heart failure that could lead to decreased chronic brain hypoperfusion (CBH) in humans [14-16], which is considered one of the main manifestations of dementia, with the exception of amyloid oligomers accumulation and neuron death [17], the mechanism of cardiogenic dementia is believed to involve the $\mathrm{CBH}[6,11,18,19]$. Whether other non-CBH mechanisms mediate heart disease-induced cognitive impairment remains largely unknown.

Our previous study demonstrated that heart-specific microRNA-1 (miR-1) overexpression in transgenic mice, induced an increase in miR-1 levels in the hippocampus and cognitive impairment by exerting direct effects on the brain [20]. Because it has been reported that $m i R$-1 plays an important role in MI-induced arrhythmia [21] and heart failure [22], and plasma miR-1 was found to be increased in the blood of patients suffering from acute myocardial infarction (AMI) [23-25], we hypothesized that miR-1 may participate in MI mediated brain dysfunction. In this study, we found that MI mice had decreased memory abilities and attenuated long-term potential (LTP). The molecular mechanism was the increased $m i R-1$ level in the hippocampi of MI mice.

\section{Materials and Methods}

\section{Animals}

Adult male C57BL/6 mice (6-7 months, $6 \mathrm{M}$ or $7 \mathrm{M}$ ) were housed under controlled temperature of (23 $\pm 1^{\circ} \mathrm{C}$ ) and humidity $(55 \pm 5 \%)$ and maintained on a $12 \mathrm{~h}$ artificial dark-light cycle (lights on at 07:00 A.M.) with food (regular chow) and water available ad libitum. The mouse line of heart-specific over-expression of miR-1 transgenic (Tg) mice (male, $5 \sim 6$ months) was kindly provided by Prof. Xu Gao (Harbin Medical University). Tg mice were generated as previous reported [26]. Hippocampal samples for quantitative realtime reverse transcription polymerase chain reaction (qRT-PCR) and western blot analysis were obtained from mice after they were anesthetized with sodium pentobarbital $(100 \mathrm{mg} / \mathrm{kg}$, i.p.). Animals were sacrificed and confirmed by exsanguination. All animal procedures were approved by Harbin Medical University. All procedures were carried out in accordance with the European Communities Council Directive of November 24, 1986 (86/609/EEC).

\section{Mouse model of myocardial infarction}

A myocardial infarction (MI) mouse model was generated as previously described [21]. Briefly, 5- to 6-month-old male C57BL/6 mice were anesthetized with sodium pentobarbital ( $40 \mathrm{mg} / \mathrm{kg}$, intraperitoneal). After the heart was exposed, the left coronary artery was ligated using a 7-0 silk suture. The elevated ST segment of the electrocardiograph (ECG) was used as the index to evaluate the successful development of the MI animal model. Sham-operated control mice underwent the same procedures except that the suture placed under the left coronary artery was not tied. All surgical procedures were performed under aseptic conditions. 


\section{Cellular Physiology Cell Physiol Biochem 2018;50:1601-1616 \begin{tabular}{l|l|l} 
and Biochemistry Published online: 26 October 2018 & $\begin{array}{l}\text { ○ 2018 The Author(s). Published by S. Karger AG, Basel } \\
\text { www.karger.com/cpb }\end{array}$ \\
\hline
\end{tabular}}

Ma et al.: Myocardial Infarction Impairs Memory in Mice

\section{Passive avoidance tasks}

The passive avoidance test was performed in the apparatus consisting of light and dark chambers connected via a sliding door. (PAT-8, Chengdu Taimeng Software Co.Ltd., China). In the acquisition trial, mice were individually placed into the light compartment and adapted for $30 \mathrm{~s}$. The sliding door was opened, and the mice that entry into the dark compartment were paired with electrical foot shock (2 V) provided through the metal grid covering the floor. Then the mice returned to the bright chamber immediately. The time taken to enter the dark room (for a maximum of $120 \mathrm{~s}$ ) was recorded, and mice that failed to enter the dark chamber within 90s were excluded. After $24 \mathrm{~h}$, during the retention trial, no electrical stimuli were used, that is, the electrical stimuli were removed from the dark chamber. Mice were placed into the light compartment, and the step-through latency was measured $[27,28]$.

\section{Active avoidance tasks}

The apparatus (STT-100, Chengdu Taimeng Software Co.Ltd., China) was divided into two identical shuttle-compartments of the same size $(14.3 \mathrm{~cm} \times 15.5 \mathrm{~cm} \times 21 \mathrm{~cm})$ connected by a gate $(4 \mathrm{~cm} \times 3.7 \mathrm{~cm})$. A conditioned stimulus (CS, coincident presentation of a $3.6 \mathrm{~W}$ light and a $90 \mathrm{~dB}$ sound) was delivered $10 \mathrm{~s}$ before the unconditioned stimulus (US, a 2 V electrical foot shock) and overlapped it for $5 \mathrm{~s}$. At the end of the stimulus presentation, both the CS and US were terminated, and the cycle began in the other compartment. Animals were subjected to five daily 30 -cycle sessions with a 20 s cycle interval. On the sixth day, the cycle was performed without electric foot shock. An avoidance response was recorded when the animal avoided the US by running into the dark compartment within $10 \mathrm{~s}$ after the onset of the CS [27].

\section{Surgical Procedures and Placement of Electrodes}

Under urethane anaesthesia (1.2 $\mathrm{g} / \mathrm{kg}$ body weight, supplemental doses of $0.2 \sim 0.8 \mathrm{~g} / \mathrm{kg}$ as needed), mice were mounted on the stereotaxic frame apparatus (DW-2000, Chengdu Taimeng Software Co.Ltd., China) for the insertion of electrodes. For local anaesthesia, procainhydrochloride (1\%) was injected subcutaneously into the tissue around the incision before surgery. To maintain the body temperature of mice at $37^{\circ} \mathrm{C}$, a heating pad was placed under the mouse. After drilling holes in the skull, a bipolar stimulation electrode (stainless steel, tip separation $0.5 \mathrm{~mm}$ ) for stimulating the perforant pathway was implanted into the brain ( $2.1 \mathrm{~mm}$ lateral to midline, $3.8 \mathrm{~mm}$ posterior to bregma; and $1.5 \sim 1.8 \mathrm{~mm}$ below the brain surface). The recording electrode filled with $3 \mathrm{~mol} / \mathrm{L} \mathrm{NaCl}$ was placed in the granule cell layer of the dentate gyrus (DG) (1.7 mm posterior to the bregma, $1.0 \mathrm{~mm}$ lateral to the midline, $1.5 \sim 1.8 \mathrm{~mm}$ below the brain surface). The depth of the stimulating and recording electrodes was adjusted to obtain the maximal response.

\section{Electrophysiological Recording}

Monopulse stimulations (duration $0.1 \mathrm{~ms}$ ) were generated using a stimulus generator BL-420S (Chengdu Taimeng Software Co.Ltd., China). Population spikes (PS) recorded the granule cell of the DG were amplified by a ME-1 preamplifier (Chengdu Taimeng Software Co.Ltd., China). The current signal was filtered ( $1 \mathrm{~Hz}-1 \mathrm{kHz}$ ), digitized at $20 \mathrm{kHz}$, and recorded in the computer by BL-420S. To establish the input -output (I/O) curves, we used stimulation strengths that ranged from 5 to $30 \mathrm{~V}$. The response interval was 30 $\mathrm{s}$, and the amplitude of the PS was averaged and represented by using three responses at each stimulation strength. The amplitude of the PS was defined as the average of the amplitude from the first positive peak (a) to the first negative peak (b) and the amplitude from the negative peak (b) to the second positive peak (c): $[(a-b)+(c-b)] / 2$. Based on this curve, the stimulus strength which corresponds to the $50 \%$ maximum amplitude of PS was used to plot a baseline for $20 \mathrm{~min}$ (two responses per min) and record long term potentiation (LTP). For LTP induction, a theta-burst stimulation (TBS) protocol was performed, which comprised six series of six trains of six pulses at $400 \mathrm{~Hz}$, with $200 \mathrm{~ms}$ between trains, and $20 \mathrm{~s}$ between series, and a pulse width and stimulus intensity that were doubled during the TBS in comparison to baseline recordings. After TBS, the evoked responses were recorded for an additional $60 \mathrm{~min}$ (one response per min) $[29,30]$. 


\section{Cellular Physiology Cell Physiol Biochem 2018;50:1601-1616

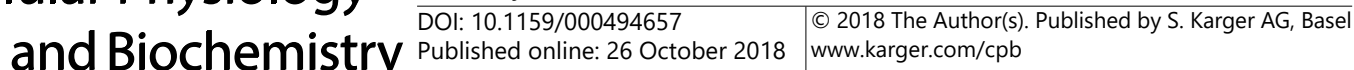 \\ Published online: 26 October 2018 wars}

\section{Construction of lentivirus vectors}

To produce a miR-1 antisense inhibitor, two single-stranded DNA oligonucleotides were designed as follows: (1) pre-AMO-miR-1 ("top strand" oligo: tgctgATACATACTTCTTTACATTCCAGTTTTGGCCACTGACTGACTGGAATGTAGAAGTATGTAT) and its complementary sequence ("bottom strand" oligo: cctgATACATACTTCTACATTCCAGTCAGTCAGTGGCCAAAACTGGAATGTAAAGAAGTATGTATc); and (2) scrambled RNA (mis-AMO-1) was used as a negative control ("top strand" oligo: tgctgAAATGTACTGCGCGTGGAGACGTTTTGGCCACTGACTGACGTCTCCACGCAGTACATTT) and its complementary sequence ("bottom strand" oligo: cctgAAATGTACTGCGTGGAGACGTCAGTCAGTGGCCAAAACGTCTCCACGCGCAGTACATTTc). Doublestranded oligonucleotides (ds oligos) were generated by annealing the top and bottom strand oligos into a pcDNA ${ }^{\mathrm{Tm}} 6.2-\mathrm{GW} / \pm$ EmGFP-miR vector and transforming the ligated construct into competent Escherichia coli, using a BLOCK-iT pol II miR RNAi expression vector and an EmGFP kit from Invitrogen (Shanghai, China). After the colony was purified and identified as the correct expression clone, the pre-miRNA expression cassette was transferred to a Gateway ${ }^{\circledR}$ adapted destination vector utilizing Pol II promoters to form a new miRNA expression clone containing attR substrates. The vector was identified by analysing the plasmid sequence (Invitrogen, Shanghai, China). The lenti-pre-AMO-1 vectors used for the experiments (2.0 $\mu \mathrm{L}$ ) contained $1.0 \times 10^{8}$ transducing units (TUs) $/ \mathrm{mL}$. Virus suspensions were stored at $-80^{\circ} \mathrm{C}$ until use and were briefly centrifuged and kept on ice immediately before injection.

\section{Stereotactic injection of lentiviral vectors}

After anaesthesia, 5- to 6- month-old male mice were placed onto a stereotaxic frame (RWB Life Science Co. Ltd., China) [31]. Lentiviral vectors were administered into the bilateral CA1 area of the hippocampus using a $5 \mu \mathrm{L}$ Hamilton syringe with a 33-gauge tip needle at $2.2 \sim 2.5 \mathrm{~mm}$ below the surface of the dura. The injection coordinates relative to bregma were as follows: anteroposterior (AP), $-2.8 \mathrm{~mm}$; mediolateral (ML), $\pm 3.0 \mathrm{~mm}$; and dorsoventral (DV), $2.2-2.5$; Hamilton, Bonaduz, Switzerland. The needle was maintained in place for $2 \mathrm{~min}$ after the injection and was then very softly withdrawn to avoid backflow of the solution. The accuracy of the injection sites was confirmed by direct stereotaxic injection of Evans blue (Sigma Chemical Co., St. Louis, Missouri, USA) into the hippocampus CA1 subfield. After 1 month, the mice were used for the subsequent experiments.

\section{Primary culture of neonatal rat hippocampal and cortical neurons (NRNs)}

The primary culturing of NRNs was performed according to procedures that have been previously described in detail [31]. Briefly, hippocampal and cortical regions were collected from Sprague-Dawley (SD) rat pups at postnatal day 0 (P0) after administration of $20 \%$ isoflurane and confirmation of death by cervical dislocation and placed immediately into phosphate-buffered saline (PBS) on ice. They were then dissected and incubated in the presence of $0.125 \%$ trypsin (Gibco, USA) for $15 \mathrm{~min}$ in water bath at $37^{\circ} \mathrm{C}$. After dispersion, cells were plated in six-well plates pre-coated with $10 \mu \mathrm{g} / \mathrm{mL}$ poly-D-lysine (Sigma, USA). The cells were maintained in culture media containing neurobasal medium (Gibco, USA) with $2 \%$ B27 supplement (Invitrogen, USA) and $10 \%$ foetal bovine serum (FBS, HyClone, Logan, UT) at a density of 1 3 $\times 10^{5} \mathrm{cells} / \mathrm{cm}^{2}$. The cultures were incubated in a $37^{\circ} \mathrm{C}$ humidified chamber that was maintained at 5 $\% \mathrm{CO}_{2}$. They were fed by exchanging $50 \%$ of the culture media twice a week. Neurons were treated with $5 \mu \mathrm{M}$ cytosine arabinoside (Sigma, USA) after 3 days in culture to inhibit astrocyte proliferation. For all experiments, neurons were used at 5-7 days after plating.

Oligonucleotide Synthesis

MiR-1 mimics for rats (sense: 5'-UGGAAUGUAAAGAAGUGUGUAUGU-3'; antisense: 5'-AUACACACUUCUUUACAUUCCAAU- $3^{\prime}$ ) and AMO-1 (5'-ACCUUACAUUUCUUCACACAUACA-3') were synthesized by Shanghai GenePharma Co., Ltd. (Shanghai, China). AMO-1 contains 2'-O-methyl modifications. In addition, scrambled RNA (mis-miR-1) was used as a negative control (sense: 5'-UUCUCCGAACGUGUCACGUAA-3'; antisense: 5'-ACGUGACACGUUCGGAGAAUU-3'). 


\section{Cellular Physiology Cell Physiol Biochem 2018;50:1601-1616 \begin{tabular}{l|l|l} 
and Biochemistry Published online: 26 October 2018 & $\begin{array}{l}\text { (c) } 2018 \text { The Author(s). Published by S. Karger AG, Basel } \\
\text { www.karger.com/cpb }\end{array}$ \\
\hline
\end{tabular}}

Ma et al.: Myocardial Infarction Impairs Memory in Mice

\section{Transfection procedures}

A dose of $75 \mathrm{pmol} / \mathrm{mL}$ miR-1, NC siRNA or diethyl phosphorocyanidate (DEPC) water was transfected into NRNs with X-treme GENE siRNA transfection reagent (Cat.\# 04476093001, Roche, USA) according to the manufacturer's instructions [22, 31]. Cells were collected for protein purification at $48 \mathrm{~h}$ post-transfection.

TaqMan quantitative real-time RT-PCR.

The $m i R-1$ level was quantified by the TaqMan ${ }^{\circ}$ MicroRNA Reverse Transcription Kit (Cat.\#4366596, Applied Biosystems) and the TaqMan ${ }^{\circledR}$ Gene Expression Master Mix (for rats: target sequences: UGGAAUGUAAAGAAGUGUGUAU, Cat.\#002064; for mouse; UGGAAUGUAAAGAAGUAUGUAU, Cat.\#002222 Applied Biosystems). We used U6 (Cat.\#001973, Applied Biosystems) as an internal control. The PCR protocol was as follows: (1) $95{ }^{\circ} \mathrm{C}$ for $10 \mathrm{~min}$, and (2) $95{ }^{\circ} \mathrm{C}$ for $15 \mathrm{~s}$ and $60{ }^{\circ} \mathrm{C}$ for $1 \mathrm{~min}$ (repeat (2) for 40 cycles). The $\delta-\delta$ Ct method was used to calculate the relative expression levels of $m i R-1$ normalized with U6 [32].

Western blot analysis

Total protein samples for western blot analysis were extracted from the hippocampi of the mice or from primary cultured NRNs, and the procedure for the preparation of total protein has been described previously [20]. Frozen brain tissues were lysed in a solution containing $10 \%$ SDS, $60 \%$ RIPA, $1 \%$ protease inhibitor and $10 \%$ phosphatase inhibitor. For primary cultured NRNs, samples were treated in a solution containing RIPA, $1 \%$ protease inhibitor and $10 \%$ phosphatase inhibitor after collection by a cell scraper. The homogenate was then centrifuged at $16700 \times \mathrm{g}$ at $4^{\circ} \mathrm{C}$ for $30 \mathrm{~min}$ and the supernatants (containing cytosolic and membrane fractions) were collected. The concentration of proteins was detected spectrophotometrically using a BCA kit (Universal Microplate Spectrometer; Bio-Tek Instruments, Winooski, VT, USA). Protein samples were fractionated by $10 \%$ SDS-PAGE gels, and then transferred onto a polyvinylidene fluoride (PVDF) membrane. Anti-BDNF (1:1000, ab108319, Abcam, MA, USA), anti-GluR1 (1:1000, 13185, Cell Signaling, USA) and anti-p-GluR1 ser-831 (1:1000, 04-823, Millipore, USA) were used as primary antibodies. $\beta$-actin (1:1000, AT-09, ZSGB-BIO, China) was selected as an internal control. Blots were detected with an Odyssey Infrared Imaging System (Licor, USA) and quantified with Odyssey v1.2 software by measuring the protein intensity (area $\times$ optical density) in each group. The final results were expressed as fold changes compared with the control values.

\section{Statistical analysis}

The data were described as the Mean \pm SEM. Day-by-day comparisons between-group were performed using factorial ANOVA (split-plot design) after performing Mauchly's test of sphericity with a $P>0.05$. If the Mauchly's test of sphericity was $P<0.05$, multivariate analysis of variance MANOVA was performed and Post hoc analyses of significant main effects were further performed using Fisher's Least Significant Difference (LSD) tests. Two-tailed Student's t-test was applied for comparisons between the two groups for both electoral physiological and western blot analysis. A $P<0.05$ was considered statistically significant. SAS 9.1 software (serial number: 989155; Institute Inc. China) was used for all statistical analyses.

\section{Results}

\section{Reduction of learning and memory in mice with myocardial infarction}

To explore whether myocardial infarction (MI) could induce an impairment in cognition, we developed an MI animal model by ligatiing the left coronary artery (LCA) for 4 weeks. Previous studies reported that passive avoidance behaviour requires the association between a normally neutral environment and an aversive stimulus, and is dependent on hippocampal function $[27,28,33,34]$. In this experiment, mice were trained to escape the conditioning chamber with the foot shock. We found that, compared with the latency in the sham group, the escape latency of passive avoidance in the MI group was significantly decreased (Fig. 1A, $P$ $<0.05)$. Since the active avoidance test is a Pavlovian conditioning task that involves contextdependent memory, and this behaviour requires the integrity of hippocampal function [35]. Throughout the active avoidance test, the data showed that not only the percentage of mice 
Fig. 1. Learning and memory impairment in MI mice assessed by passive and active avoidance tests. (A) Comparison of escape latency for the sham group and MI group in the passive avoidance test. (B) Percentages of successfully avoidance of foot shock for mice in the sham and MI group during training phases in the active avoidance test. (C) Mean daily latencies to successfully avoid foot shock during training phases in the active avoidance test. (D) Retention latency and mean percent of trials with foot shock avoidance during testing phases in the active avoidance test. $* \mathrm{P}<0.05$ versus sham group, $\mathrm{n}=8$ for the sham group, $\mathrm{n}=9$ for the MI group, values are expressed as the mean \pm SEM.
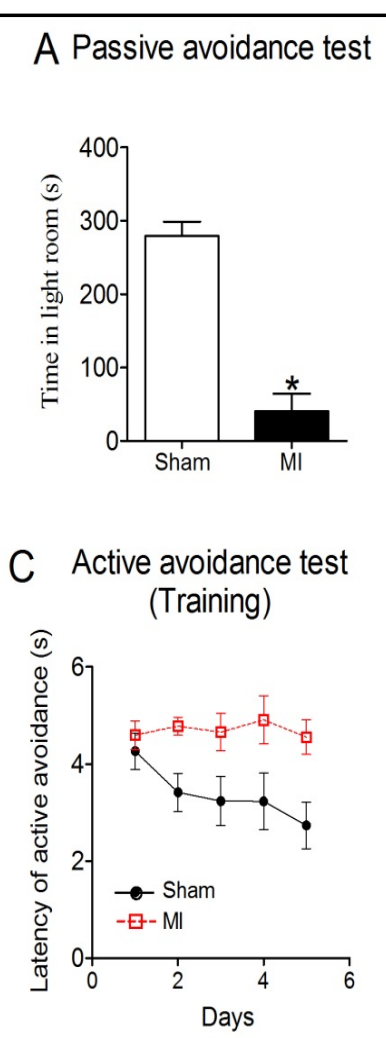
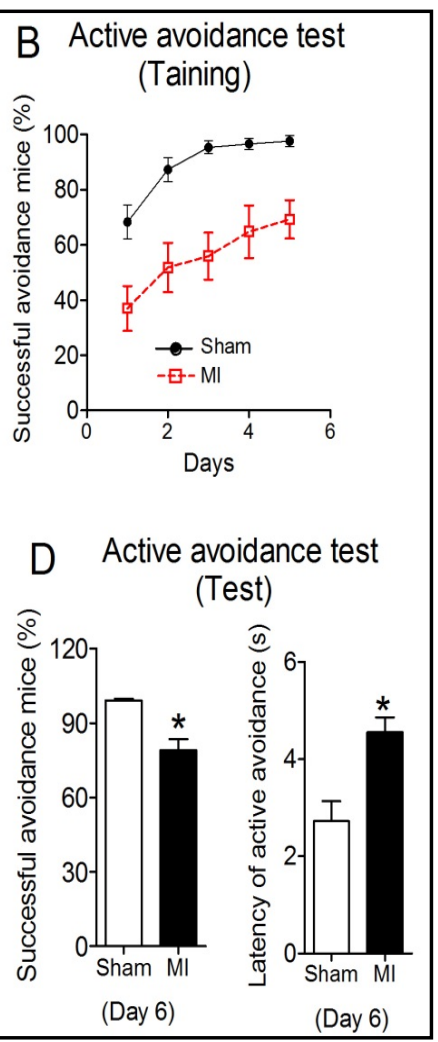

showing active avoidance was significantly decreased (Fig. $1 \mathrm{~B}, \mathrm{~F}_{(1.17)}=21.73, P<0.0001$ ) but also the latency to active avoidance was markedly prolonged in the MI group relative to the sham group during days 1 to 5 of training (Fig. $1 \mathrm{C}, \mathrm{F}_{(1,17)}=7.76, P=0.0136$ ). During test day 6 , MI mice had a significantly lower foot shock avoidance percentage and longer latency than sham mice (Fig. 1D). These results suggest that MI could induce memory deficits.

Attenuation of theta-burst stimulation (TBS)-induced long-term potentiation (LTP) in MI mice

Synaptic transmission is the basis of memory formation and storage. To address whether synaptic transmission is involved in MI-induced memory deficits, synaptic function was investigated. We first evaluated the basal synaptic transmission by stimulating the perforant pathway (PP) with increasing voltage intensities (from 5 to $30 \mathrm{~V}$ ) and recording the population spikes (PS) at the granular cell layer of the dentate gyrus (DG) in vivo (Fig. 2A). As illustrated in Fig. 2B-D, the analysis of stimulus-response curves showed a similar latency and duration of the PS in MI mice relative to the age-matched sham group $(P>0.05)$. However, the PS amplitude was significantly reduced in MI mice compared to sham mice although they all presented significantly elevated PS amplitude following the gradually increased stimulation intensities (Fig. 2E and F). These results suggested that MI inhibited the effectiveness of basal synaptic transmission, however, it did not affect the speed of basal synaptic neurotransmitter release or the postsynaptic response in the PP-DG path of mice.

To observe whether MI could affect the efficiency of synaptic transmission, the TBS protocol, which was considered as the more suitable technique to dissect the mechanism of physiological pattern inputs [36], was performed to elicit LTP. The results showed that a clear TBS-LTP induction was observed (Fig. 2G and H), and this TBS-LTP lasted for at least 1 $\mathrm{h}$ in both sham and MI mice (Fig. $2 \mathrm{H}$ ). However, the PS amplitude was significantly lower in MI mice than in sham mice after LTP induction (Fig. $2 \mathrm{H}$ and I). The results indicated that MI could lead to decreased enhancement of the efficiency of synaptic transmission induced by TBS in the PP-DG path. 
Fig. 2. Electrophysiological alterations at excitatory perforant pathway synapses in MI mice. (A) Illustration depicting the stimulation and recording electrode placement. (B) The representative curve of population spikes (PS) from sham and MI mice, respectively. (C) The latency of the PS during determination of the inputoutput curves. (D) The duration of the PS during determination of the input-output curves. (E) Input-output curves of PS amplitude recorded in the dentate gyrus (DG) area. The synaptic responsiveness of PS amplitude in MI mice was decreased compared with the sham group. (F) Qualification of the data from (E). ${ }^{*} \mathrm{P}<0.05$ versus sham group, $\mathrm{n}=7$ for the sham group, $\mathrm{n}=8$ for the MI group. (G) The representative curve of population spikes (PS) of theta-burst stimulation (TBS) induced long-term potentiation (LTP) from sham and MI mice. (H) The LTP induced by TBS (TBS-LTP) was decreased in the MI group compared with sham group. The potentiation of PS amplitude is presented as a percentage change of the baseline (\%) before TBS (arrow). (I) Quantification of the data from $(\mathrm{H})$. The LTP
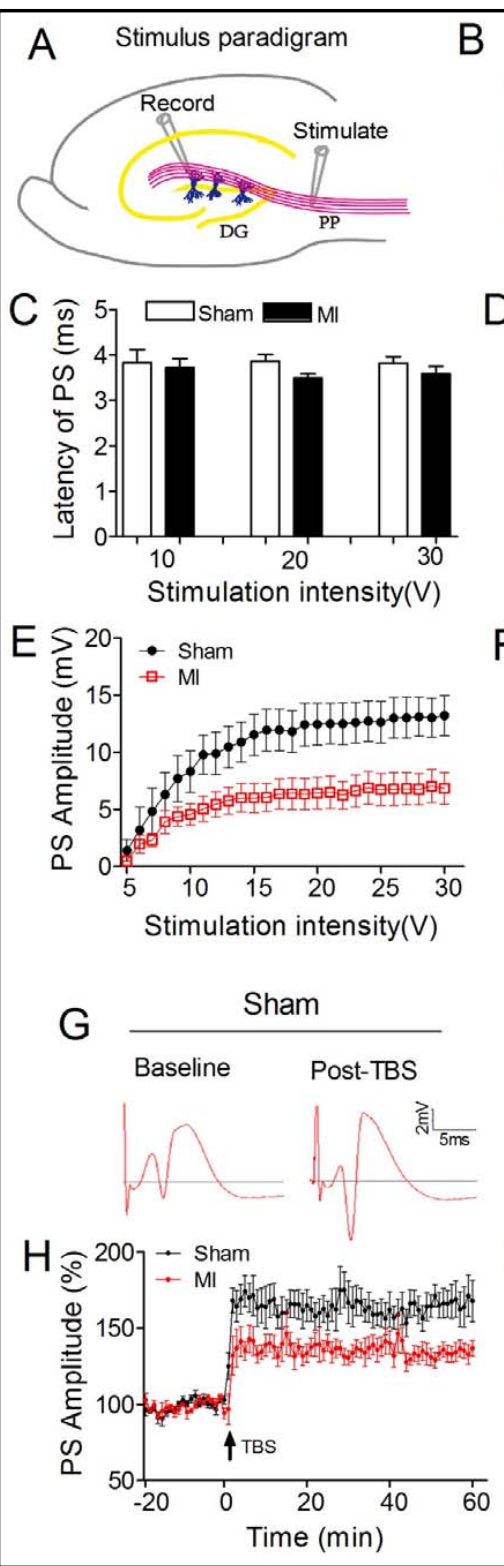
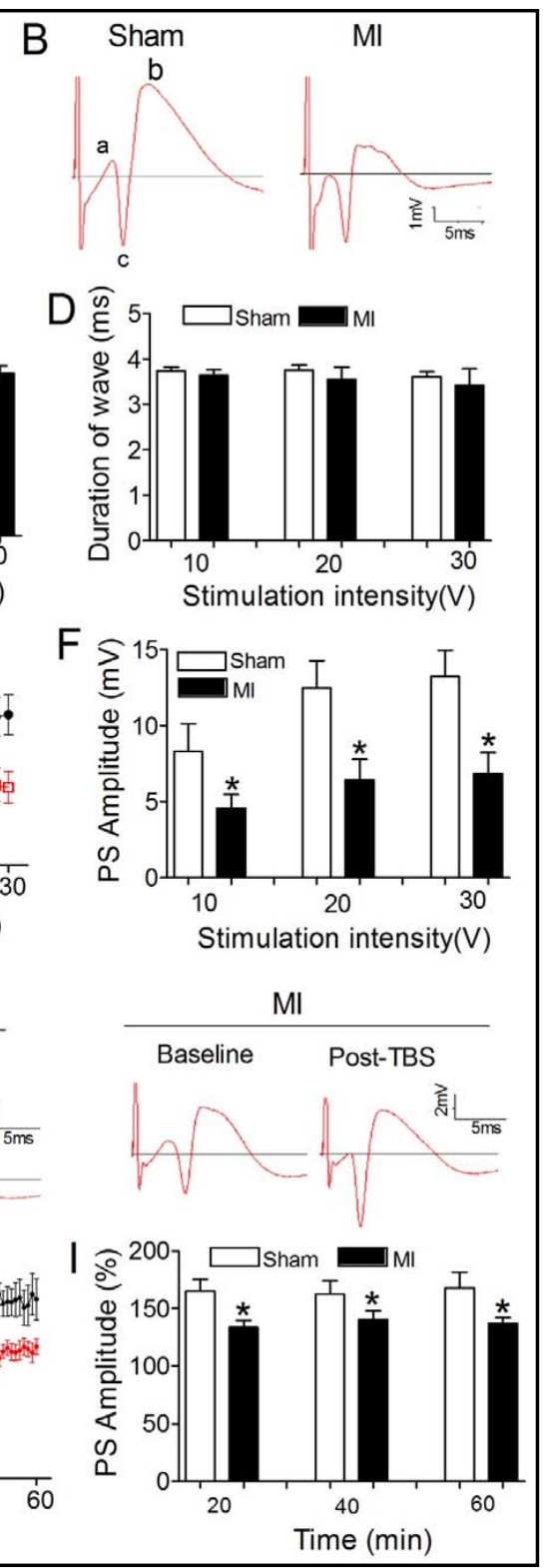
assessed by PS amplitude was weaker in the MI group compared with the sham group after the delivery of TBS $(20 \mathrm{~min}, 40 \mathrm{~min}$ and 60 min). ${ }^{*} \mathrm{P}<0.05$ versus sham group, $\mathrm{n}=7$ for the sham group, $\mathrm{n}=6$ for the MI group, values are expressed as the mean \pm SEM.

\section{Attenuation of cognition and TBS-LTP in cardiac-specific overexpressed miR-1 transgenic mice}

Previously, miR-1 has been reported to be increased in the blood of both AMI rats and patients $[23,25,37]$, and cardiac-specific over-expression of $m i R-1$ could induce cognitive impairment compared with age-matched WT mice using the Morris water maze test [20]. We hypothesized that the attenuation of TBS-LTP following 4 weeks of MI might be associated with $m i R-1$. To explore this issue, we employed a transgenic (Tg) mouse line for the cardiacspecific over-expression of miR-1-2, which was driven by an $\alpha$-myosin heavy chain ( $\alpha$-MHC) promoter [22], and we also evaluated the memory of these Tg mice that experienced the same evaluation method as the MI mice. As descried in Fig. 3A, compared with age-matched wild type (WT) mice, we demonstrated that the escape latency for passive avoidance of $m i R$ - 


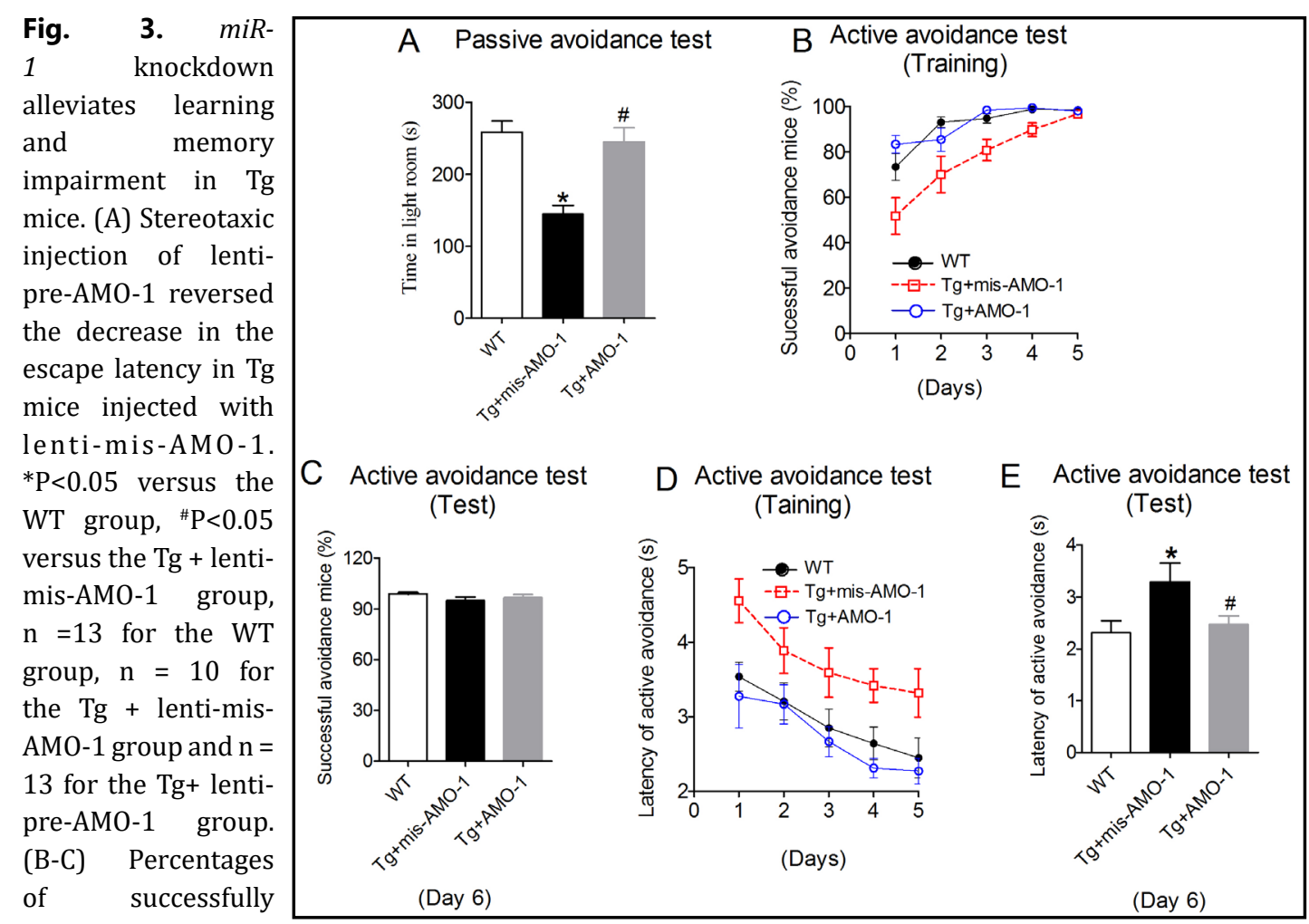

avoiding foot shock

mice during the training phases (B) and testing phases(C) in the active avoidance test. (D) Analysis of mean daily latencies in the active avoidance test. A significant increase in the mean daily latencies of $\mathrm{Tg}+$ lentimis-AMO-1 mice compared with WT mice, whereas lenti-pre-AMO-1 treatment attenuated the mean daily latency enhancement. (E) Comparison of retention latency on the test day in the active avoidance test. ${ }^{*} \mathrm{P}<0.05$ versus the WT group, ${ }^{*} \mathrm{P}<0.05$ versus the $\mathrm{Tg}+$ lenti-mis-AMO- 1 group, $\mathrm{n}=10$ for each group, values are expressed as the mean \pm SEM.

$1 \mathrm{Tg}$ mice was significantly decreased, an effect that was prevented by stereotaxic injection of anti-miR-1 oligonucleotide fragments carried by a lentivirus vector (lenti-pre-AMO-miR-1) directly into the CA1 area of the hippocampus (latency of PAV: $250 \pm 5.34,139 \pm 3.45$ and $221 \pm 7.97$, in WT, Tg + lenti-mis-AMO-1 and Tg + lenti-pre-AMO-1 mice, respectively;. $\mathrm{F}=$ $12.91, P<0.0001)$. Interestingly, although the percentage of active avoidance response by the $\mathrm{Tg}$ mice was lower than age-matched WT mice before the $4^{\text {th }}$ day of training, the percentage reached $98.3 \%$ at the $5^{\text {th }}$ day (Fig. $3 \mathrm{~B}, \mathrm{~F}_{(1,18)}=12.809, P=0.002$ ). In addition, there was no difference in successful avoidance between WT and Tg group on the test day (Fig. 3C, $\mathrm{F}=2.420, P=0.100$ ). Similar to MI mice, $\mathrm{Tg}$ mice had significantly increased latenciesy of active avoidance response during training from the first day to the $5^{\text {th }}$ day (Fig. $3 \mathrm{D}, \mathrm{F}_{(1,18)}=$ 10.758, $P=0.004$ ) and in the test day 6 (Fig. 3E, $P=0.026$ ). Importantly, all these changes in Tg mice were reversed by directly and stereotaxically injecting lenti-pre-AMO-1 into the hippocampus (Fig. 3B: $\mathrm{F}_{(2,27)}=11.504, P<0.0001$, D: $\mathrm{F}_{(2,27)}=10.856, P<0.0001$ and $\mathrm{E}: \mathrm{F}=$ $4.089, P=0.026)$. These results suggest that Tg mice mimic a similar memory decline as MI mice, which is associated with increased miR-1 levels in the hippocampus.

We then evaluated whether Tg mice presented attenuated basal synaptic transmission and TBS-LTP in the PP-DG path. We found that, contrast to MI mice, the latency and duration of the PS as well as the PS amplitude were not changed in $\mathrm{Tg}$ mice that injected with lenti-mis-AMO-1 relative to age-matched WT mice (Fig. 4A-C). These results suggest that overexpression of miR-1 in the heart does not affect basal synaptic transmission in the PP-DG path. However, TBS induced LTP was significantly decreased in Tg mice injected with lenti-mis-AMO-1 which was inverted by lenti-pre-AMO-1 treatment (Fig. 4D-E). These 


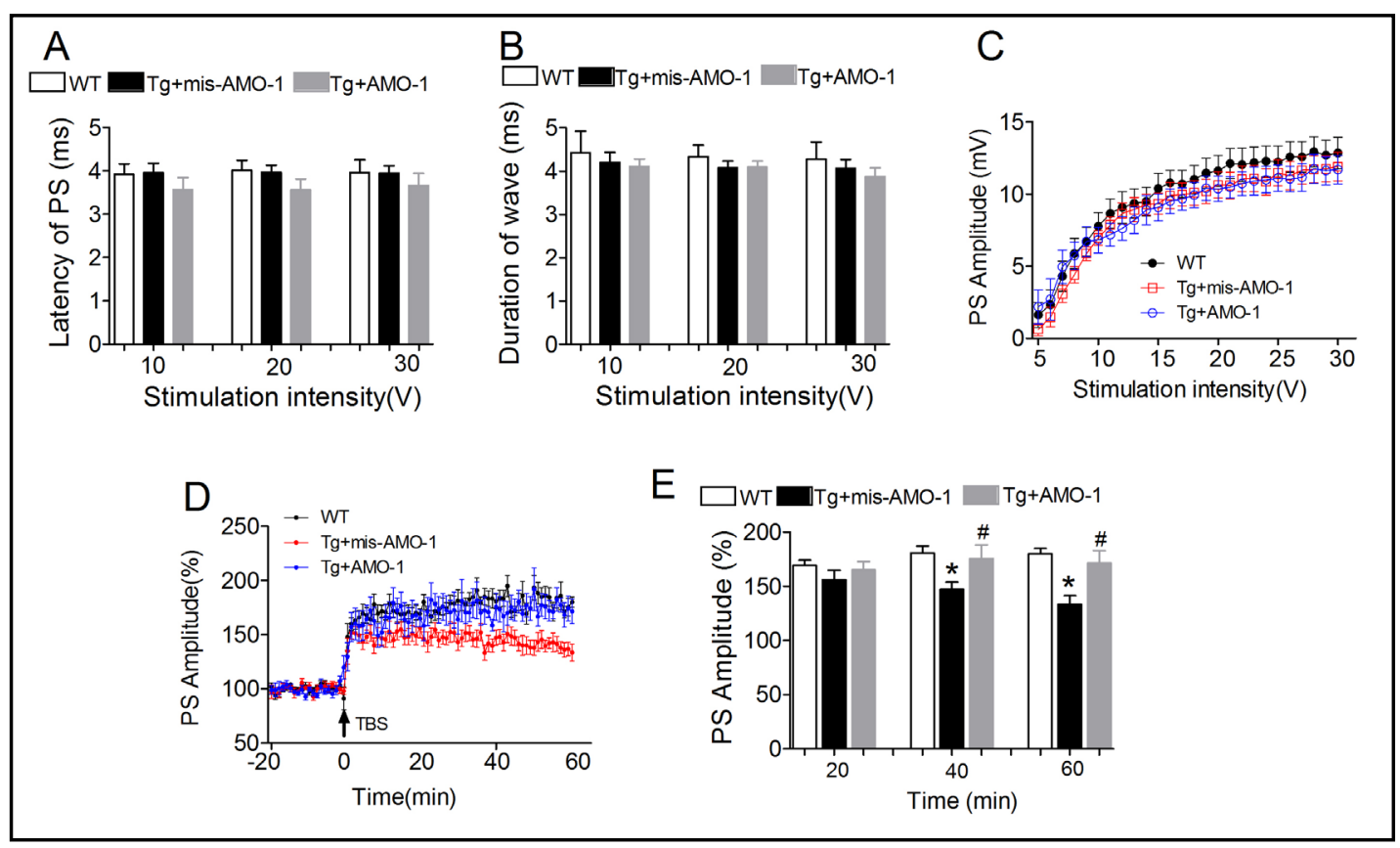

Fig. 4. miR-1 knockdown attenuates the TBS-LTP deficits in Tg mice. (A) The latency of PS drawn from the input-output curves. (B) The duration of the PS drawn from the input-output curves. (C) Input-output curves of the PS amplitude plotted by perforant path stimulation. $\mathrm{N}=9$ for the WT and Tg + lenti-mis-AMO-1 groups and $n=6$ for the Tg + lenti-pre-AMO-1 group. (D) TBS-LTP was decreased in Tg + lenti-mis-AMO-1 mice, whereas lenti-pre-AMO-1 treatment ameliorated this reduction. (E) Quantification of the data from (D). The mean percentage changes of PS at $20 \mathrm{~min}, 40 \mathrm{~min}$ and $60 \mathrm{~min}$ after TBS. ${ }^{*} \mathrm{P}<0.05$ versus WT group, ${ }^{\#} \mathrm{P}<0.05$ versus $\mathrm{Tg}+$ lenti-mis-AMO-1 group, $\mathrm{n}=9$ for $\mathrm{WT}$ and $\mathrm{Tg}+$ lenti-mis-AMO- 1 group and $\mathrm{n}=8$ for the $\mathrm{Tg}+$ lenti-pre-AMO-1 group, values are expressed as the mean $\pm \mathrm{SEM}$.

results indicate that overexpression of $m i R-1$ in the heart could induce decreased efficiency of synaptic transmission associated with increased miR-1 levels in the hippocampus.

It has been demonstrated that the molecular basis of TBS-LTP is related to BDNF signalling by binding with the TrkB receptor and phosphorylating GluA1 [38, 39]. Our previous study demonstrated that cardiac over-expression of miR-1 downregulated BDNF expression in the hippocampus [20]. Thus, we speculated that the reduced LTP in Tg mice might be associated with BDNF, which mediated the decreased phosphorylation of GluA1 (p-GluA1). As predicted, we observed that the expression levels of BDNF, p-GluA1, and GluA1 protein were significantly decreased in the hippocampi of Tg mice compared with the WT group, which was prevented by the injection of lenti-pre-AMO-1 (Fig. 5A). We then further investigated the action of $m i R-1$ in vitro. For this purpose, $m i R-1$ and/or AMO-1 were directly transfected into NRNs using X-treme GENE siRNA transfection reagent. Immunoblotting analysis showed that $m i R-1$ effectively inhibited the expression of all BDNF, p-GluA1 and GluA1 proteins relative to their levels in the control group, whereas the scrambled negative control mis-miR-1 failed to affect the protein levels (Fig. 5B-D). In contrast, miR-1-mediated downregulation of these proteins was rescued by AMO-1 (Fig. 5B-D).

miR-1 is involved in the attenuation of cognition and TBS-LTP in MI mice

Based on the above results, we speculated that the disrupted cognition and LTP in MI mice might result from overexpression of $m i R-1$. To address this issue, lenti-pre-AMO-miR-1 was directly stereotaxically injected into the hippocampi of MI mice. We found that the $m i R-1$ levels were significantly increased in the hippocampi of MI mice, an effect that was prevented by lenti-pre-AM0-1 injection (Fig. $6 \mathrm{~A}, \mathrm{~F}=89.6, P<0.0001$ ). As illustrated in Fig. 6B, lentipre-AMO-1 treatment effectively prevented the decreased escape latency of lenti-mis-AMO-1 
Fig. 5. Overexpression of $\quad m i R-1$ inhibits the expression of TBS-LTP re levant proteins. (A) The expression of BDNF, GluA1 and $\mathrm{p}$-GluA1 in hippocampi e valuat ed by western blot. ${ }^{*} \mathrm{P}<0.05$ versus the WT group,

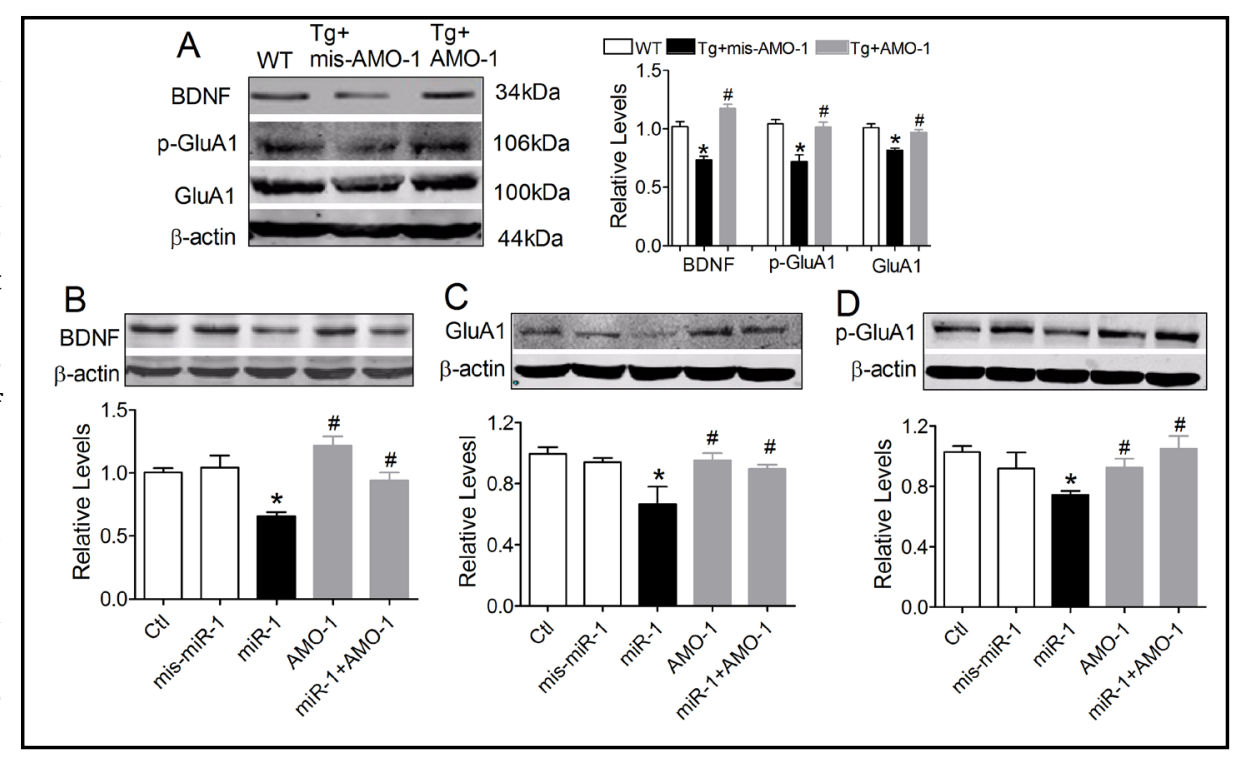
${ }^{\#} \mathrm{P}<0.05$

versus the Tg group, $n=6$ animals per group. (B-D) The protein levels of BDNF (B), GluA1(C) and p-GluA1 (D) in primary cultured NRNs transfected with miR-1, AM0-1, miR-1 + AMO-1, or mis-miR-1, which was measured by western blot analysis. ${ }^{*} \mathrm{P}<0.05$ versus $\mathrm{Ctl}$, ${ }^{*} \mathrm{P}<0.05$ versus miR- $1, \mathrm{n}=3$ batches of cells for each group. Values are expressed as the mean \pm SEM.

Fig. 6. Inhibition of $m i R$ 1 ameliorates learning and memory impairment in MI mice. (A) The relative levels of $m i R$ 1 in the hippocampi of MI mice and lenti- preAMO-1 treated MI mice, as measured by qRT-PCR. ${ }^{*} \mathrm{P}<0.05$ versus sham group, ${ }^{~} \mathrm{P}<0.05$ versus $\mathrm{MI}+$ lenti-mis-AMO-1 group, $\mathrm{n}$ $=6$ animals per group. (B) Stereotaxic injection of lenti-pre-AMO-1 into the hippocampi enhanced the escape latency of MI mice with lenti-mis-AMO-1 in the passive avoidance test. (C-D) Lenti-pre-AMO-1 treatment prevented the decreased latency of mice in both training phases (C) and testing day (D) in the

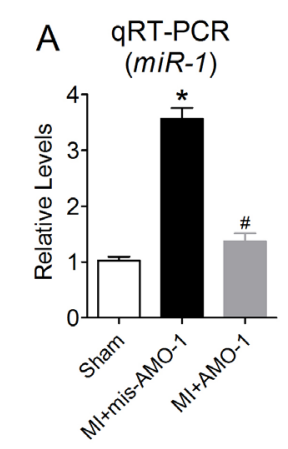

D Active avoidance tes (Test)

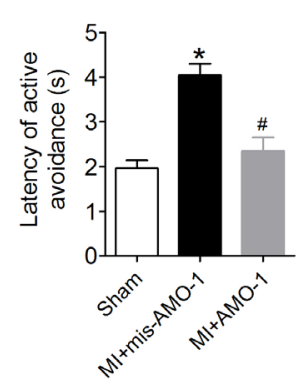

(Day 6)

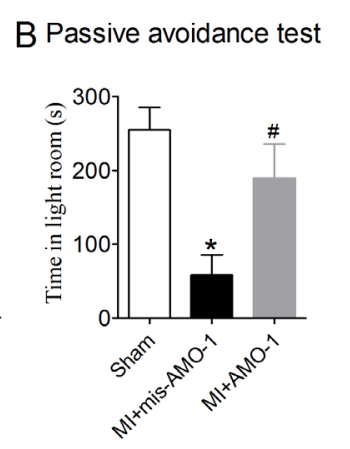

E Active avoidance test (Taining)

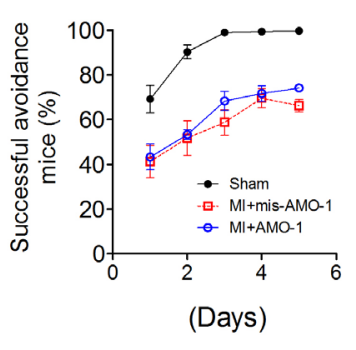

(Days)

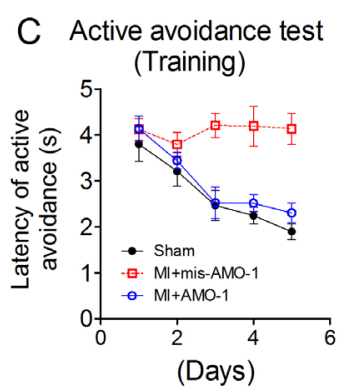

F Active avoidance test

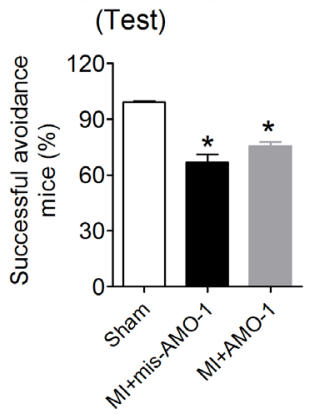

(Day 6) active avoidance test. (E-

F) Lenti- pre-AMO-1 treatment did not affect the decreased percentage of MI with lenti-mis-AMO-1 mice in both training phases (E) and testing day (F) in the active avoidance test. ${ }^{*} \mathrm{P}<0.05$ versus the sham group, ${ }^{\#} \mathrm{P}<0.05$ versus the MI + lenti-mis-AMO-1 group, $\mathrm{n}=10$ for the sham group, $\mathrm{n}=8$ for the MI+ lenti-misAMO-1 and MI+ lenti-pre-AMO-1 group, values are expressed as the mean \pm SEM. 
treated MI mice in the passive avoidance test $(F=8.199, P=0.0021)$. Surprisingly, for active avoidance test, lenti-pre-AMO-1 treatment effectively prevented the prolonged avoidance latency of lenti-mis-AMO-1 treated MI mice (Fig. 6C: $\mathrm{F}_{(1,16)}=1.055, P=0.321$; MI+ lenti-misAMO-1 vs MI+AMO-1: $\mathrm{F}_{(1,14)}=15.448, P=0.002$ and $\mathrm{D}: \mathrm{F}=20.35, P<0.0001$ ) though it failed to improve the reduced percentage of mice showing an active avoidance response (Fig. 6E: sham $v s \mathrm{MI}+\mathrm{AMO}-1: \mathrm{F}_{(1,16)}=116.383, P<0.0001$; MI+ lenti-mis-AMO-1 vs MI+AMO-1: $\mathrm{F}_{(1,14)}$ $=0.909, P=0.357 \&$ F: MI+ lenti-mis-AMO-1 vs MI+AMO-1, P > 0.05). These results suggest that inhibition of $m i R-1$ level in the hippocampi of MI mice could ameliorate the MI-induced memory deficit.

By using the same strategies, we investigated miR-1 action on basal synaptic transmission. We found that lenti-pre-AMO-1 injection failed to improve the reduced PS amplitude of lenti-mis-AMO-1 treated MI mice following increased electrical stimulation intensities (Fig. $7 \mathrm{~A}$ and B), suggesting that over-expression of miR-1 in the hippocampi of MI mice did not participate in the weakened effectiveness of basal synaptic transmission in the PP-DG path of MI mice. However, lenti-pre-AM0-1 injection significantly elevated the decreased LTP elicited by TBS in the PP-DG path in MI mice with lenti-mis-AMO-1 (Fig. 7C and D), suggesting that over-expression of $m i R-1$ in the hippocampi of MI mice could ameliorate MI induced attenuation of TBS-LTP. As predicted, lenti-pre-AMO-miR-1 injection successfully prevented the decreased expression of BDNF, p-GluA1 and GluA1 proteins in the hippocampi of MI mice (Fig. 7E and F).

Fig. 7. miR-1 knockdown reversed TBS-LTP impairment in MI mice. (A) Stereotaxic injection of lenti-pre-AMO-1 into the hippocampi of MI mice did not affect the depressed input-output curves of the PS amplitude of MI injection with lenti-mis-AM0-1 mice. (B) Quantification of the data from (A). ${ }^{*} \mathrm{P}<0.05$ versus sham group, $\mathrm{n}=9$ for the sham group, $n=6$ mice per group. (C) Lentipre-AMO-1 treatment into the hippocampi reversed TBS-LTP impairment in MI mice with lenti-misAMO-1. (D) Qualification of the data from (C). The mean percentage changes of population spikes at $20 \mathrm{~min}$, $40 \mathrm{~min}$ and $60 \mathrm{~min}$ after TBS. ${ }^{*} \mathrm{P}<0.05$ versus the sham group, ${ }^{\#} \mathrm{P}<0.05$ versus the $\mathrm{MI}+$ lenti-mis-AMO-1 group,

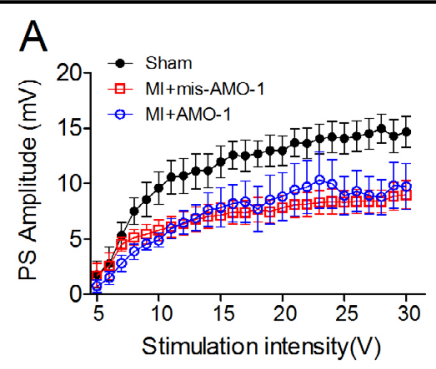

\section{$\mathrm{B}$}
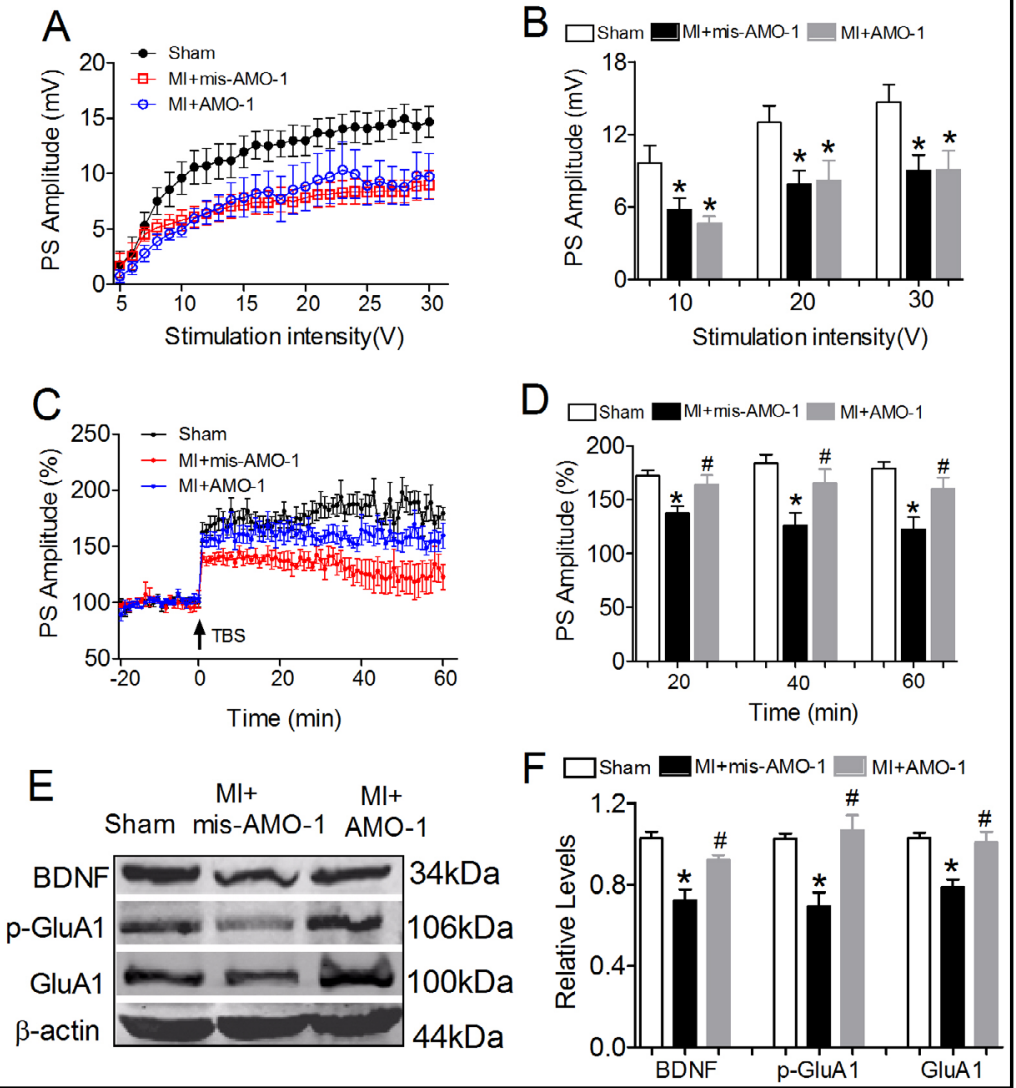

$\mathrm{n}=8$ for the sham group, $\mathrm{n}$

= 6 for the MI + lenti-mis-AMO-1 group and $\mathrm{n}=8$ for the MI + lenti-pre-AMO-1 group. (E) Lenti-pre-AMOmiR-1 treatment into the hippocampi increased the expression of BDNF, p-GluA1 and GluA1 in MI + lentimis-AM0-1 mice as measured by western blot analysis. ${ }^{*} \mathrm{P}<0.05$ versus sham group, ${ }^{*} \mathrm{P}<0.05$ versus the $\mathrm{MI}+$ lenti-mis-AM0-1 group, $\mathrm{n}=6$ animals per group, values are expressed as the mean \pm SEM. 


\section{Cellular Physiology Cell Physiol Biochem 2018;50:1601-1616 and Biochemistry Published online: 26 October 2018 \begin{tabular}{l|l} 
DOI: 2018 The Author(s). Published by S. Karger AG, Basel \\
www.karger.com/cpb
\end{tabular} \\ Ma et al.: Myocardial Infarction Impairs Memory in Mice}

\section{Discussion}

In the present study, we first reported that mice suffering from 4 weeks of myocardial infarction had decreased memory abilities and attenuated TBS-LTP. The molecular mechanism is the increased miR-1 levels in the hippocampus, which mediates the downregulation of BDNF expression, thereby dephosphorylating the GluA1 subunit of the AMPA receptor at the Ser831 site. This study provides a novel insight into the potential molecular mechanism by which MI induces cognitive deficits at the miRNA level.

Cardiovascular diseases, including hypertension, atrial fibrillation, coronary heart disease and heart failure, have been reported to be closely associated with an impairment of cognition such as vascular dementia $[7,8,10,11,19]$. Although all cardiovascular diseases share similar pathological changes, e.g., changes due to diabetes and/or hyperlipidaemia, the clinical trial results of the benefits of antihypertensive, anti-diabetic and antihyperlipidaemia treatments on cognitive impairment are controversial [12, 40,41]. Our previous study demonstrated that a mouse model with the cardiac-specific over-expression of miR-1-2 driven by $\alpha$-MHC showed impaired cognition, which was associated with increased miR-1 levels mediating downregulation of BDNF expression in the hippocampus [20]. Because miR-1 levels were increased in the heart and blood of MI mice [21, 42, 43], MIinduced brain damage was apparent on the $15^{\text {th }}$ day and cognitive deficiency was observed at 3 months after LCA [13], we hypothesized that miR-1 might be involved in MI induced brain dysfunction. By performing the passive and active avoidance tests, we found that mice, after 4 weeks of MI, presented remarkably reduced passive avoidance latencies and increased active avoidance latencies, which could be prevented by the inhibition of hippocampal miR-1 levels through stereotaxic injection of lenti-pre-AMO-miR-1 directly into the hippocampus. The results suggested that miR-1 was involved in MI-induced cognitive impairment.

Synaptic transmission is fundamental to memory formation, therefore, we recorded DG granule cell activity following perforant pathway stimulation in vivo. We found that MI mice, compared to the sham group, exhibited a reduced effectiveness on basal synaptic transmission without differences in the basal synaptic neurotransmitter release speed and postsynaptic response in the PP-DG path. Since TBS mimics the physiological patterns of afferent activity, it was considered more suitable to dissect mechanisms of synaptic plasticity in vivo [36, 44]. In the present study, after performing TBS protocols, we found that, relative to sham controls, MI mice showed a decreased TBS-induced LTP. Surprisingly, although hippocampal injection of lenti-pre-AMO-miR-1 effectively improved the attenuated TBS-LTP of MI mice, it failed to prevent impaired basal synaptic transmission. To clarify this issue, Tg mice with cardiac-specific overexpression of miR-1 were used, and we found that although Tg mice had a reduced TBS-LTP response, which was improved by hippocampal treatment with lenti-preAMO-miR-1, the mice did not display any changes in basal synaptic transmission, including the effectiveness, speed and postsynaptic response process. These data indicated that $m i R-1$ participated in MI resulted in memory deficits, but it was not the unique regulator. There is other mechanisms might involve in this process that needs to be clarified further.

The most commonly accepted view of the molecular basis of LTP is that glutamate release induces a postsynaptic response. Typically, after release from presynaptic knob, glutamate binds to the AMPA receptor leading to depolarization by displacing magnesium from the NMDA receptor and triggering the opening of the NMDA receptor. This allows $\mathrm{Ca}^{2+}$ influx and triggers the subsequent insertion of additional AMPA receptor into the membrane by phosphorylation of the GluA1 subunit at Ser831 and strengthens potentiation [39]. Interestingly, BDNF is a key regulator of cognition due to its participation in hippocampal LTP [45, 46], including TBS-induced LTP [47]. More importantly, it has been demonstrated that BDNF initiates early LTP by enhancing the surface expression of GluA1 and regulates late LTP via the phosphorylation of CREB [45]. Our previous study revealed that BDNF is a target of $m i R-1$ [20]. In this study, we found that $m i R-1$ levels were increased, while, BDNF protein expression was significantly reduced in the hippocampi of MI mice, indicating that $m i R-1$ can inhibit BDNF protein expression in MI mice. A previous study revealed that 


\section{Cellular Physiology

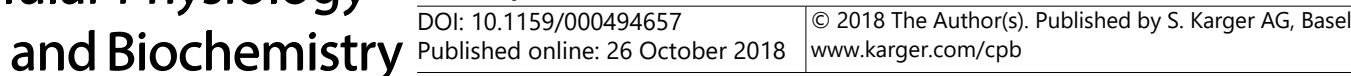

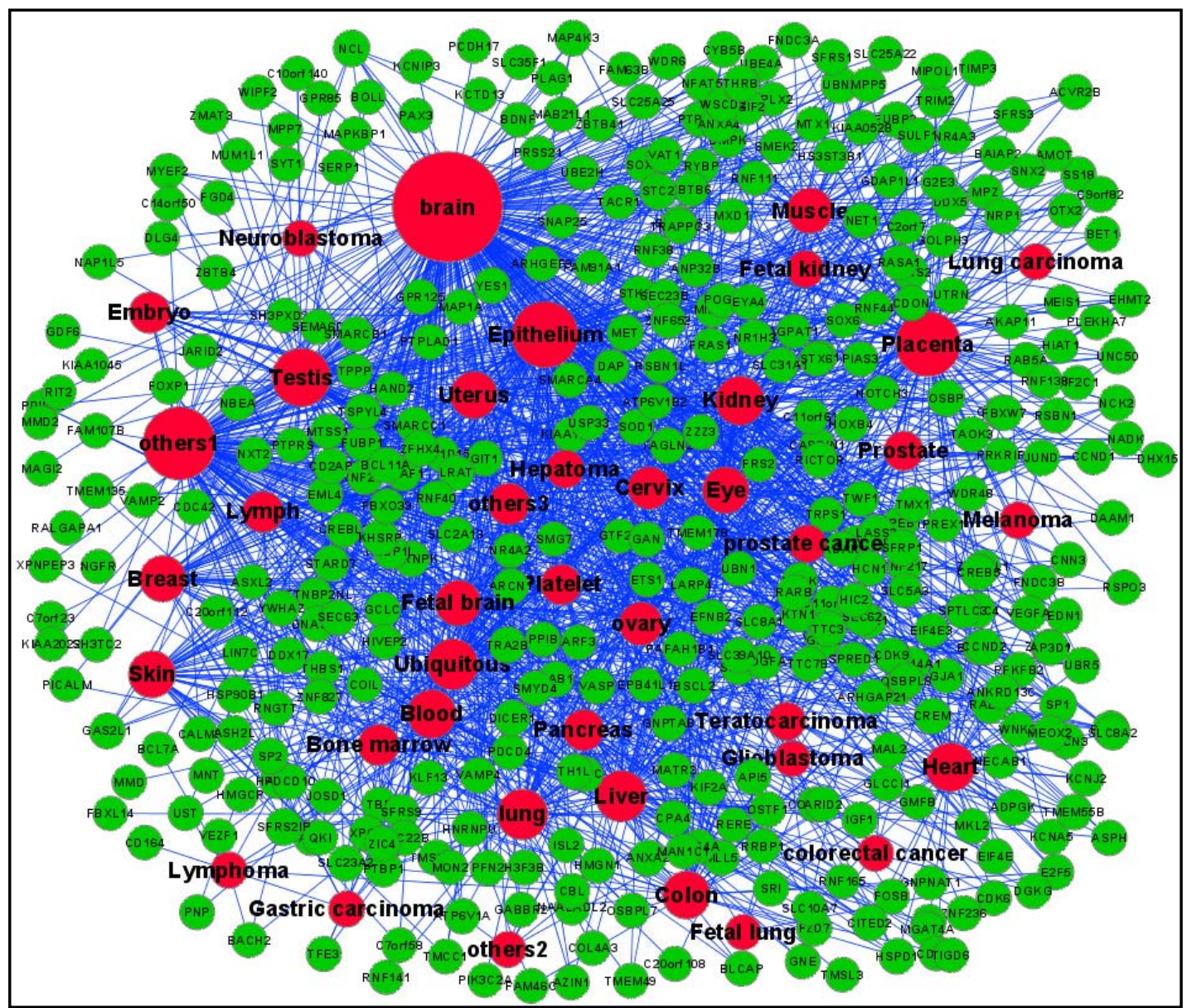

Fig. 8. The PPI network of miR-1 targets. Targetscan 5.1 was used to find miR-1 targets. To interpret the biological function of the miR-1 targets, GO analysis was performed using Gene Ontology Enrichment Analysis Software Toolkit (GOEAST), which is a web-based software toolkit with providing analysis results via generating graphs exhibiting enriched GO terms as well as their relationships in the whole GO hierarchical tree. In addition, Database for Annotation, Visualization, and Integrated Discovery (DAVID, http://david. abcc.ncifcrf.gov) was also used to conduct GO terms functional analysis with displaying gene names for a given gene list. The red node represents $m i R-1$ target-distributed tissues. The node size represents the degree of distributed genes. The green node represents miR-1 targets. PPI: protein-protein interaction.

BDNF acutely upregulated GluA1 expression by activating mTOR kinase [48] and inducing GluA1 phosphorylation on Ser-831 through activation of protein kinase $\mathrm{C}$ and $\mathrm{Ca}^{2+}$ calmodulin-dependent protein kinase II $[49,50]$. In this study, we found decreased GluA1 and p-GluA1-831 protein in MI and Tg mice, which could be prevented by lenti-pre-AMO$m i R-1$ treatment in the hippocampi of mice. These results suggest that miR-1 indirectly regulates the expression of GluA1 and p-GluA1-831 by inhibiting the expression of BDNF. However, because miR-1 has multi-targets (Fig. 8) [51], we cannot exclude other miR-1 targets that participate in MI-induced impaired cognition. For example, our previous study demonstrated that MI also leads to hippocampal microtubule dissolution by targeting the tubulin polymerization promoting protein (TPPP/p25) gene [32], which plays a major role in maintaining the stability of neuronal microtubules by inducing tubulin polymerization into normal and double-walled microtubules and inducing their bundling [52]. Whether and how the other miR-1 targets participate in MI induced cognitive decline needs to be clarified in the future. 


\section{Cellular Physiology Cell Physiol Biochem 2018;50:1601-1616

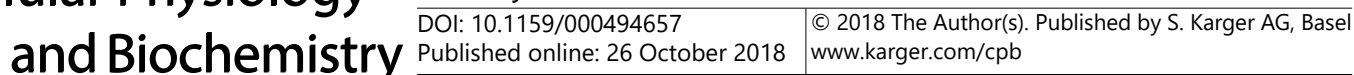 \\ Ma et al.: Myocardial Infarction Impairs Memory in Mice}

\section{Acknowledgements}

This work was supported by Natural Science Foundation of China $(81671052,81870849$, 81471115 and 81271207 to J. A.).

\section{Disclosure Statement}

Thea authors declare no competing interests.

\section{References}

1 Cardiogenic dementia. Lancet 1977;1:27-28.

2 Bink DI, Ritz K, Aronica E, van der Weerd L, Daemen MJ: Mouse models to study the effect of cardiovascular risk factors on brain structure and cognition. J Cereb Blood Flow Metab 2013;33:1666-1684.

3 de Toledo Ferraz Alves TC, Ferreira LK, Wajngarten M, Busatto GF: Cardiac disorders as risk factors for alzheimer's disease. J Alzheimers Dis 2010;20:749-763.

4 Bhat NR: Linking cardiometabolic disorders to sporadic alzheimer's disease: A perspective on potential mechanisms and mediators. J Neurochem 2010;115:551-562.

5 Nyberg J, Aberg MA, Schioler L, Nilsson M, Wallin A, Toren K, Kuhn HG: Cardiovascular and cognitive fitness at age 18 and risk of early-onset dementia. Brain 2014;137:1514-1523.

6 Bleckwenn M, Kleineidam L, Wagner M, Jessen F, Weyerer S, Werle J, Wiese B, Luhmann D, Posselt T, Konig HH, Brettschneider C, Mosch E, Weeg D, Fuchs A, Pentzek M, Luck T, Riedel-Heller SG, Maier W, Scherer M: Impact of coronary heart disease on cognitive decline in alzheimer's disease: A prospective longitudinal cohort study in primary care. The British journal of general practice : the journal of the Royal College of General Practitioners 2017;67:e111-e117.

7 Sundboll J, Hovath-Puho E, Adelborg K, Schmidt M, Pedersen L, Botker HE, Henderson VW, Sorensen HT: Higher risk of vascular dementia in myocardial infarction survivors. Circulation 2018;137:567-577.

8 Liu E, Dyer SM, O’Donnell LK, Milte R, Bradley C, Harrison SL, Gnanamanickam E, Whitehead C, Crotty M: Association of cardiovascular system medications with cognitive function and dementia in older adults living in nursing homes in australia. Journal of geriatric cardiology: JGC 2017;14:407-415.

-9 Laudisio A, Marzetti E, Pagano F, Cocchi A, Bernabei R, Zuccala G: Digoxin and cognitive performance in patients with heart failure: A cohort, pharmacoepidemiological survey. Drugs Aging 2009;26:103-112.

10 Roberts RO, Knopman DS, Geda YE, Cha RH, Roger VL, Petersen RC: Coronary heart disease is associated with non-amnestic mild cognitive impairment. Neurobiol Aging 2010;31:1894-1902.

11 de la Torre JC: Cardiovascular risk factors promote brain hypoperfusion leading to cognitive decline and dementia. Cardiovascular psychiatry and neurology 2012;2012:367516.

12 Schievink SHJ, van Boxtel MPJ, Deckers K, van Oostenbrugge RJ, Verhey FRJ, Kohler S: Cognitive changes in prevalent and incident cardiovascular disease: A 12-year follow-up in the maastricht aging study (maas). Eur Heart J DOI:10.1093/eurheartj/ehx365.

$>13$ Hong X, Bu L, Wang Y, Xu J, Wu J, Huang Y, Liu J, Suo H, Yang L, Shi Y, Lou Y, Sun Z, Zhu G, Behnisch T, Yu M, Jia J, Hai W, Meng H, Liang S, Huang F, Zou Y, Ge J: Increases in the risk of cognitive impairment and alterations of cerebral beta-amyloid metabolism in mouse model of heart failure. PLoS One 2013;8:e63829.

14 Jefferson AL, Himali JJ, Beiser AS, Au R, Massaro JM, Seshadri S, Gona P, Salton CJ, DeCarli C, O’Donnell CJ, Benjamin EJ, Wolf PA, Manning WJ: Cardiac index is associated with brain aging: The framingham heart study. Circulation 2010;122:690-697.

15 Polidori MC, Mariani E, Mecocci P, Nelles G: Congestive heart failure and alzheimer's disease. Neurol Res 2006;28:588-594.

16 Gardarsdottir M, Sigurdsson S, Aspelund T, Rokita H, Launer LJ, Gudnason V, Arnar DO: Atrial fibrillation is associated with decreased total cerebral blood flow and brain perfusion. Europace DOI:10.1093/europace/ eux220. 


\section{Cellular Physiology Cell Physiol Biochem 2018;50:1601-1616 \begin{tabular}{l|l|l} 
DOI: 10.1159/000494657 & O 2018 The Author(s). Published by S. Karger AG, Basel \\
mww karger.com/cpb
\end{tabular} and Biochemistry Published online: 26 October 2018 werch}

17 Daulatzai MA: Cerebral hypoperfusion and glucose hypometabolism: Key pathophysiological modulators promote neurodegeneration, cognitive impairment, and alzheimer's disease. J Neurosci Res 2017;95:943972.

$>18$ Jefferson AL: Cardiac output as a potential risk factor for abnormal brain aging. J Alzheimers Dis 2010;20:813-821.

19 Monsuez JJ, Gesquiere-Dando A, Rivera S: Cardiovascular prevention of cognitive decline. Cardiol Res Pract 2011;2011:250970.

20 Ma JC, Duan MJ, Sun LL, Yan ML, Liu T, Wang Q, Liu CD, Wang X, Kang XH, Pei SC, Zong DK, Chen X, Wang $\mathrm{N}, \mathrm{Ai}$ J: Cardiac over-expression of microrna-1 induces impairment of cognition in mice. Neuroscience 2015;299:66-78.

-21 Yang B, Lin H, Xiao J, Lu Y, Luo X, Li B, Zhang Y, Xu C, Bai Y, Wang H, Chen G, Wang Z: The muscle-specific microrna mir-1 regulates cardiac arrhythmogenic potential by targeting gja1 and kcnj2. Nat Med 2007;13:486-491.

22 Ai J, Zhang R, Gao X, Niu HF, Wang N, Xu Y, Li Y, Ma N, Sun LH, Pan ZW, Li WM, Yang BF: Overexpression of microrna-1 impairs cardiac contractile function by damaging sarcomere assembly. Cardiovasc Res DOI:10.1093/cvr/cvs196.

23 Ai J, Zhang R, Li Y, Pu J, Lu Y, Jiao J, Li K, Yu B, Li Z, Wang R, Wang L, Li Q, Wang N, Shan H, Yang B: Circulating microrna-1 as a potential novel biomarker for acute myocardial infarction. Biochem Biophys Res Commun 2010;391:73-77.

24 Cheng Y, Tan N, Yang J, Liu X, Cao X, He P, Dong X, Qin S, Zhang C: A translational study of circulating cellfree microrna-1 in acute myocardial infarction. Clin Sci (Lond) 2010;119:87-95.

25 Liebetrau C, Mollmann H, Dorr O, Szardien S, Troidl C, Willmer M, Voss S, Gaede L, Rixe J, Rolf A, Hamm C, Nef H: Release kinetics of circulating muscle-enriched micrornas in patients undergoing transcoronary ablation of septal hypertrophy. J Am Coll Cardiol 2013;62:992-998.

-26 Ai J, Zhang R, Gao X, Niu HF, Wang N, Xu Y, Li Y, Ma N, Sun LH, Pan ZW, Li WM, Yang BF: Overexpression of microrna-1 impairs cardiac contractile function by damaging sarcomere assembly. Cardiovasc Res 2012;95:385-393.

27 Wang J, Zhang X, Cheng X, Cheng J, Liu F, Xu Y, Zeng J, Qiao S, Zhou W, Zhang Y: Lw-afc, a new formula derived from liuwei dihuang decoction, ameliorates cognitive deterioration and modulates neuroendocrine-immune system in samp8 mouse. Curr Alzheimer Res 2017;14:221-238.

28 Stubley-Weatherly L, Harding JW, Wright JW: Effects of discrete kainic acid-induced hippocampal lesions on spatial and contextual learning and memory in rats. Brain Res 1996;716:29-38.

29 Jedlicka P, Vnencak M, Krueger DD, Jungenitz T, Brose N, Schwarzacher SW: Neuroligin-1 regulates excitatory synaptic transmission, ltp and epsp-spike coupling in the dentate gyrus in vivo. Brain structure \& function 2015;220:47-58.

-30 Jedlicka P, Schwarzacher SW, Winkels R, Kienzler F, Frotscher M, Bramham CR, Schultz C, Bas Orth C, Deller $\mathrm{T}$ : Impairment of in vivo theta-burst long-term potentiation and network excitability in the dentate gyrus of synaptopodin-deficient mice lacking the spine apparatus and the cisternal organelle. Hippocampus 2009;19:130-140.

-31 Ai J, Sun LH, Che H, Zhang R, Zhang TZ, Wu WC, Su XL, Chen X, Yang G, Li K, Wang N, Ban T, Bao YN, Guo F, Niu HF, Zhu YL, Zhu XY, Zhao SG, Yang BF: Microrna-195 protects against dementia induced by chronic brain hypoperfusion via its anti-amyloidogenic effect in rats. J Neurosci 2013;33:3989-4001.

-32 Sun LL, Duan MJ, Ma JC, Xu L, Mao M, Biddyut D, Wang Q, Yang C, Zhang S, Xu Y, Yang L, Tian Y, Liu Y, Xia SN, Li KX, Jin Z, Xiong Q Ai J: Myocardial infarction-induced hippocampal microtubule damage by cardiac originating microrna-1 in mice. J Mol Cell Cardiol 2018;120:12-27.

-33 Chen C, Kim JJ, Thompson RF, Tonegawa S: Hippocampal lesions impair contextual fear conditioning in two strains of mice. Behavioral neuroscience 1996;110:1177-1180.

-34 Impey S, Smith DM, Obrietan K, Donahue R, Wade C, Storm DR: Stimulation of camp response element (cre)-mediated transcription during contextual learning. Nat Neurosci 1998;1:595-601.

-35 Olton DS: Specific deficits in active avoidance behavior following penicillin injection into hippocampus. Physiol Behav 1970;5:957-963.

-36 Larson J, Lynch G: Role of n-methyl-d-aspartate receptors in the induction of synaptic potentiation by burst stimulation patterned after the hippocampal theta-rhythm. Brain Res 1988;441:111-118. 


\section{Cellular Physiology Cell Physiol Biochem 2018;50:1601-1616

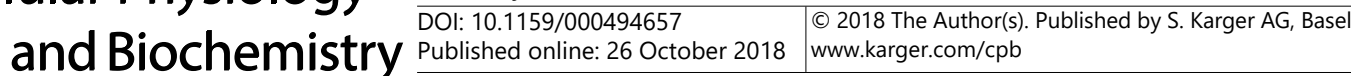 \\ Published online: 26 October 2018 www.karger.com/cpb}

37 Cheng Y, Tan N, Yang J, Liu X, Cao X, He P, Dong X, Qin S, Zhang C: A translational study of circulating cellfree microrna-1 in acute myocardial infarction. Clin Sci (Lond) 2010;119:87-95.

-38 Bramham CR, Messaoudi E: Bdnf function in adult synaptic plasticity: The synaptic consolidation hypothesis. Prog Neurobiol 2005;76:99-125.

-39 Henley JM, Wilkinson KA: Ampa receptor trafficking and the mechanisms underlying synaptic plasticity and cognitive aging. Dialogues Clin Neurosci 2013;15:11-27.

40 Duron E, Hanon 0: Antihypertensive treatments, cognitive decline, and dementia. J Alzheimers Dis 2010;20:903-914.

-41 McGuinness B, Passmore P: Can statins prevent or help treat alzheimer's disease? J Alzheimers Dis 2010;20:925-933.

42 Jaguszewski M, Osipova J, Ghadri JR, Napp LC, Widera C, Franke J, Fijalkowski M, Nowak R, Fijalkowska M, Volkmann I, Katus HA, Wollert KC, Bauersachs J, Erne P, Luscher TF, Thum T, Templin C: A signature of circulating micrornas differentiates takotsubo cardiomyopathy from acute myocardial infarction. Eur Heart J 2014;35:999-1006.

43 Kuwabara Y, Ono K, Horie T, Nishi H, Nagao K, Kinoshita M, Watanabe S, Baba O, Kojima Y, Shizuta S, Imai M, Tamura T, Kita T, Kimura T: Increased microrna-1 and microrna-133a levels in serum of patients with cardiovascular disease indicate myocardial damage. Circ Cardiovasc Genet 2011;4:446-454.

44 Staubli U, Scafidi J, Chun D: Gabab receptor antagonism: Facilitatory effects on memory parallel those on ltp induced by tbs but not hfs. J Neurosci 1999;19:4609-4615.

45 Minichiello L: Trkb signalling pathways in ltp and learning. Nat Rev Neurosci 2009;10:850-860.

46 Bekinschtein P, Cammarota M, Medina JH: Bdnf and memory processing. Neuropharmacology 2014;76 Pt C:677-683.

47 Kang H, Welcher AA, Shelton D, Schuman EM: Neurotrophins and time: Different roles for trkb signaling in hippocampal long-term potentiation. Neuron 1997;19:653-664.

-48 Slipczuk L, Bekinschtein P, Katche C, Cammarota M, Izquierdo I, Medina JH: Bdnf activates mtor to regulate glur1 expression required for memory formation. PLoS One 2009;4:e6007.

49 Caldeira MV, Melo CV, Pereira DB, Carvalho R, Correia SS, Backos DS, Carvalho AL, Esteban JA, Duarte CB: Brain-derived neurotrophic factor regulates the expression and synaptic delivery of alpha-amino3-hydroxy-5-methyl-4-isoxazole propionic acid receptor subunits in hippocampal neurons. J Biol Chem 2007;282:12619-12628.

50 Fortin DA, Srivastava T, Dwarakanath D, Pierre P, Nygaard S, Derkach VA, Soderling TR: Brain-derived neurotrophic factor activation of cam-kinase kinase via transient receptor potential canonical channels induces the translation and synaptic incorporation of glua1-containing calcium-permeable ampa receptors. J Neurosci 2012;32:8127-8137.

51 He J, Gao Y, Wu G, Lei X, Zhang Y, Pan W, Yu H: Molecular mechanism of estrogen-mediated neuroprotection in the relief of brain ischemic injury. BMC Genet 2018;19:46.

-52 Tirian L, Hlavanda E, Olah J, Horvath I, Orosz F, Szabo B, Kovacs J, Szabad J, Ovadi J: Tppp/p25 promotes tubulin assemblies and blocks mitotic spindle formation. Proc Natl Acad Sci U S A 2003;100:13976-13981. 